\title{
UNA APROXIMACIÓN AL PATRIMONIO PROTEGIDO A FAVOR DE LA PERSONA CON DISCAPACIDAD
}

\author{
Inmaculada Vivas Tesón*
}

\begin{abstract}
RESUMEN
Dentro del espectacular avance legislativo experimentado en España en materia de discapacidad, destaca, especialmente, la Ley 41/2003, de 18 de noviembre, de protección patrimonial de las personas con discapacidad, la cual se ha ocupado de la tutela económica de la persona con discapacidad en su vertiente jurídico-privada (por tanto, al margen de la función asistencial del Estado), operando, en nuestro ordenamiento, significativas modificaciones en instituciones clásicas, como la sustitución fideicomisaria sobre la legítima estricta a favor de un descendiente incapacitado judicialmente, así como creando ex novo instrumentos negociales de enorme calado jurídico, en particular el patrimonio protegido a favor de una persona con discapacidad.
\end{abstract}

\section{DISCAPACIDAD - TUTELA ECONÓMICA - PATRIMONIO PROTEGIDO}

\section{An approximation to patrimonial protection for bandicapped people}

\section{Abstract}

In the context of Spain's amazing legal progress concerning handicapped people, the Act Nr. 41/2003 (November 18th), about patrimonial protection of handicapped people, has an important place. It deals with the economic custody of the handicapped persons from a private law's point of view (id est, apart from the welfare role of the State), involving important modifications in some classical legal institutions, such as some belonging to inheritance's law. It also created an ex novo contract instruments of great legal importance, particularly the protected patrimony for a handicapped person.

\section{HANDICAP - FINANCIAL CUSTODY - PROTECTED PATRIMONY}

* Doctora en Derecho, Profesora titular de Derecho civil de la Universidad de Sevilla, España, Facultad de Derecho, Campus de Ramón y Cajal, C/ Enramadilla 18-20, 41018, Sevilla (España), ivivas@ us.es. Artículo recibido el 28 de marzo de 2009 y aceptado para su publicación por el Comité Editorial el 18 de mayo de 2009. 


\section{INTRODUCCIÓN}

$\mathrm{S}$ i existe un sector de la población (alrededor de un 8,5\%, es decir, más de 3,8 millones de personas residentes en hogares españoles; por sexo, más de 2,30 millones de mujeres frente a 1,55 de hombres $)^{1}$ que sufre y necesita de la ayuda y apoyo de todos, éste es, sin lugar a dudas, el de las personas con discapacidad (menores, medianas y, muy especialmente, mayores, teniéndose en cuenta el progresivo envejecimiento de la población española $)^{2}$ y, no se olvide, de sus familiares (con gran frecuencia y comprensiblemente muy desorientados en este campo), que viven con enorme angustia y preocupación el futuro de sus seres queridos.

Hasta hace poco tiempo, en nuestro Código civil, encontrábamos sólo la incapacitación judicial ${ }^{3}$ de la persona y el consiguiente sometimiento a un régimen de guarda como único instrumento jurídico protector de la persona y de su patrimonio, pero dicha institución, como ha quedado largamente demostrado, no se ajusta plenamente a todas y cada una de las situaciones en las cuales puede encontrarse una persona con discapacidad, no siendo el mejor modo de dotarla de protección legal.

Afortunadamente, el legislador se ha dado cuenta de todo ello (; no siempre sucede!). De ahí que, en los últimos años, desde 2003 (declarado “Año Europeo de las personas con discapacidad" por Decisión del Consejo, de 3 de diciembre de 2001), ${ }^{4}$ nos haya obsequiado, en cumplimiento del deber de los poderes públicos de amparar los derechos fundamentales y las libertades públicas de estos ciudadanos en situación de vulnerabilidad social que impone el art. 49 de la Constitución de $1978,{ }^{5}$ con una profusa normativa con el fin de garantizar una mayor y mejor calidad de vida a las personas con discapacidad a través de medidas jurídicas que permitan brindarles autonomía y bienestar económicos. La reciente ratificación, ${ }^{6}$ por parte de España, de la Convención de Naciones Unidas sobre los Derechos de las Personas con Discapacidad hecha en Nueva York el 13 de

${ }^{1}$ Datos extraídos de la reciente Encuesta de Discapacidad, Autonomía personal y situaciones de Dependencia -EDAD- del INE del pasado mes de noviembre de 2008. Interesante es también la consulta de Jiménez Lara, A./Huete García, A.: Los discapacitados en España: Datos estadísticos. Aproximación desde la Encuesta sobre Discapacidades, Deficiencias y Estado de Salud de 1999, Ministerio de Trabajo y Asuntos Sociales, Real Patronato sobre Discapacidad, Madrid, 2003.

${ }^{2}$ V. Villagrasa Alcaide, C.: El envejecimiento de la Población y la Protección Jurídica de las Personas Mayores, Barcelona 2002, Alonso Pérez, M., Martínez Gallego, E., M ${ }^{\mathrm{a}}$ y Reguero Celada, J. (coords.): Protección jurídica de los mayores, La Ley, Madrid, 2004, y Lasarte Álvarez, C., Moretón Sanz, Ma F., y López Peláez, P. (coords.): La protección de las personas mayores, Tecnos, Madrid, 2007.

3 Preferimos ver la incapacitación en términos positivos como una forma de "capacitación", expresión muy gráfica utilizada, con gran acierto, en Alvarez Lata, N./Seoane Rodríguez, J. A.: Derecho y retraso mental. Hacia un estatuto jurídico de la persona con retraso mental, A Coruña, 1999, pág. 141.

${ }^{4}$ DOCE, Serie L, núm. 335, de 19 de diciembre de 2001.

${ }^{5}$ Para un estudio detallado de los antecedentes y significado del citado precepto constitucional, vid. De Lorenzo, R./Palacios, A.: "Discapacidad, derechos fundamentales y protección constitucional”, en Los derechos de las personas con discapacidad, Vol. I Aspectos jurídicos, Laorden, J. (dir.) y Terreros, J.L. (coord.), CGPJ, Madrid, 2007, págs. 63-79.

${ }^{6}$ BOE núm. 96, de 21 de abril de 2008, entrando en vigor, en España, el día 3 de mayo de 2008. 
diciembre de 2006 (y de su Protocolo Facultativo) ${ }^{7}$ constata su firme compromiso por promover la plena integración de las personas con discapacidad en los diferentes ámbitos de la sociedad.

Inicialmente, los familiares de una persona con discapacidad se preocupan por atender, de un modo especial, sus cuidados físicos y/o psíquicos, su personalidad y vida afectiva, su adecuada formación académica, desarrollo de aficiones y el logro de una óptima relación social. Conforme el tiempo va pasando y tales necesidades van siendo cubiertas, se hacen, con tremenda inquietud, la siguiente pregunta: " $Y$ cuando nosotros faltemos, ¿qué será de éllella?”. Dicha etapa de la vida, la adulta, es, probablemente, la más larga, razón por la cual la seguridad económica reviste una capital importancia.

Pues bien, dentro del espectacular avance legislativo en la materia, destaca, especialmente, la Ley 41/2003, de 18 de noviembre, de protección patrimonial de las personas con discapacidad ${ }^{8}$ y de modificación del Código civil, de la Ley de Enjuiciamiento civil y de la normativa tributaria (en adelante, LPPD), ${ }^{9}$ que entró en vigor al día siguiente

${ }^{7}$ V. Cabra De Luna, M. A./Bariffi, F./Palacios, A.: Derechos humanos de las personas con discapacidad: la Convención Internacional de las Naciones Unidas, Colección La Llave, Madrid, 2007, y Rubio Torrano, E.: "Convención sobre los derechos de las personas con discapacidad", en Aranzadi Civil, 2008, núm. 14, págs. 11-13.

${ }^{8}$ El uso de una terminología precisa a la hora de hablar o escribir sobre discapacidad reviste una especial trascendencia, pues, a través de la palabra, construimos pensamiento y cultura, superando viejos prejuicios y estereotipos. Nuestro legislador, quien, naturalmente, también ha experimentado una evolución terminológica (a título de ejemplo, el legislador constituyente utilizó en el art. 49 la palabra "disminuidos" y en la Ley 13/1982, de 7 de abril, de Integración Social de los Minusválidos -conocida como LISMI- se inclinó por "minusválidos"), se ha percatado de la enorme importancia de un cuidadoso uso del lenguaje en el entorno de la discapacidad y, así, ya la LPPD lleva por rúbrica "Protección patrimonial de las personas con discapacidad" (no "discapacitadas"), y en la Ley 39/2006, de 14 de diciembre de 2006, de Promoción de la Autonomía Personal y Atención a las personas en situación de Dependencia, en su Disp. Adic. 8 ${ }^{\text {a }}$, establece que las referencias contenidas en los textos normativos a los "minusválidos" y a las "personas con minusvalía" se entenderán realizadas a "personas con discapacidad", y que dicho término será el utilizado para denominarlas en las disposiciones normativas elaboradas por las Administraciones Públicas. Se trata, sin duda, de un importantísimo paso adelante del cual debemos felicitarnos.

${ }^{9}$ Es obligado hacer, aquí, un apunte legislativo. La Exposición de Motivos de la LPPD establece que "la regulación contenida en esta ley se entiende sin perjuicio de las disposiciones que pudieran haberse aprobado en las Comunidades Autónomas con Derecho civil propio, las cuales tienen aplicación preferente de acuerdo con el artículo 149.1.8 ${ }^{a}$ de la Constitución española y los diferentes estatutos de autonomía, siéndoles de aplicación esta ley con carácter supletorio, conforme a la regla general contenida en el artículo 13.2 del Código civil”. Lo así dispuesto podría pasar desapercibido si no fuera por lo que después en el articulado de la LPPD, en concreto, el art. 1, apdo. $2^{\circ}$, se preceptúa: "El patrimonio protegido de las personas con discapacidad se regirá por lo establecido en esta Ley y en sus disposiciones de desarrollo, cuya aplicación tendrá carácter preferente sobre lo dispuesto para regular los efectos de la incapacitación en los títulos IX y X del libro I del Código Civil”. Surge, de inmediato, una pregunta: ¿a qué se refiere la Ley cuando habla de "aplicación preferente" de esta norma sobre la regulación de la incapacitación?; ¿en qué lugar quedan los Derechos civiles autonómicos que hayan regulado o regulen la cuestión (la EM habla, inexplicablemente, en pasado, excluyendo aquellas normas que, tras la entrada en vigor de la LPPD, pudieran ser aprobadas sobre la materia)? Con el fin de clarificar adecuadamente tales dudas, el Parlamento de Cataluña promovió un recurso de inconstitucionalidad contra el citado art. 1 , apdo. $2^{\circ}$ de la LPPD, recurso de inconstitucionalidad 
de su publicación, ${ }^{10}$ la cual se ha ocupado de la tutela económica de la persona con discapacidad en su vertiente jurídico-privada (por tanto, al margen de que el Estado despliegue la necesaria función asistencial cuando proceda a través de prestaciones sociales, subvenciones, ayudas, etc.), operando, en nuestro Ordenamiento jurídico, significativas modificaciones en instituciones clásicas y creando ex novo instrumentos negociales de indudable calado jurídico. ${ }^{11}$

Dicha Ley permite prever y planificar el bienestar económico de las personas con discapacidad adoptando soluciones de protección patrimonial que, en el futuro, puedan, eficazmente, complementar los ingresos económicos que ellas mismas obtengan por su trabajo o por prestaciones públicas de diversa índole ${ }^{12} \mathrm{y}$, por consiguiente, permitirle vivir mejor su vida adulta.

No es preciso, pues, esperar a formularse angustiosamente la pregunta: “ ¿qué será de éllella cuando no pueda hacerme cargo o me muera?”, para iniciar la planificación económica de su etapa adulta, pues este proyecto de futuro puede comenzarse desde la niñez o adolescencia de la persona con discapacidad, contando, incluso, con algunas (aunque ridículas y, por tanto, escasamente incentivadoras) ventajas fiscales ${ }^{13}$.

Tales valiosos recursos legales encierran, en sí mismos, una gran potencialidad que debe ser plenamente disfrutada en beneficio de las personas con discapacidad y, con la perspectiva que proporciona el paso ya de cinco años desde la aprobación de la LPPD, creemos que aún son muy desconocidos. Es muy necesario que las personas con discapacidad y sus familiares (con gran frecuencia y comprensiblemente muy desorientados en este campo) conozcan adecuadamente y, de este modo, puedan utilizar las distintas

núm. 1004/2004 que, siendo admitido a trámite por el Tribunal Constitucional mediante Providencia de 13 de abril de 2004 (BOE núm. 102, de 27 de abril de 2005), está, hoy, pendiente de resolución.

${ }^{10}$ BOE núm. 277, de 19 de noviembre.

${ }^{11}$ A tales mecanismos previstos en la LPPD se añaden otros, como la hipoteca inversa, figura jurídica importada del Derecho anglosajón creada por la Ley 41/2007, de 7 de diciembre, por la que se modifica la Ley 2/1981, de 25 de marzo, de Regulación del Mercado Hipotecario y otras normas del sistema hipotecario y financiero, de regulación de las hipotecas inversas y el seguro de dependencia y por la que se establece determinada norma tributaria (BOE núm. 294, de 8 de diciembre).

${ }^{12}$ Como afirma Gallego Domínguez, I.: “Aproximación al patrimonio protegido del discapacitado”, en Protección jurídica patrimonial de las personas con discapacidad, coord. por J. Pérez De Vargas, La Ley-Actualidad, Madrid, 2007, pág. 115, "las medidas recogidas en esta Ley están presididas por una idea base: la necesidad de complemento de las medidas públicas y privadas en la protección de los discapacitados. En los últimos tiempos parecía haber un predominio de las medidas públicas de protección sobre las privadas. El legislador, consciente del grave problema derivado del creciente número de discapacitados, constatando que el Estado y, en general, las Administraciones Públicas no pueden atender todas las crecientes necesidades de estas personas necesitadas de un modo adecuado, vuelve sus ojos - no necesariamente misericordiosos-al propio patrimonio del discapacitado y de sus familiares, establece y potencia medidas propias del Derecho privado".

${ }^{13}$ La LPPD contiene una serie de exenciones, beneficios, deducciones y reducciones en los Impuestos de la Renta de las Personas Físicas, Sociedades, Transmisiones Patrimoniales y Actos Jurídicos Documentados (no, curiosamente, en el Impuesto de Sucesiones y Donaciones), aplicables a los periodos impositivos iniciados a partir del 1 de enero de 2004, con el fin de favorecer las aportaciones a título gratuito a los patrimonios protegidos, si bien tales incentivos fiscales son claro ejemplo de una notable tacañería. 
herramientas privadas de tutela patrimonial ${ }^{14}$ que el Derecho Civil ofrece a fin de garantizar una mayor y mejor calidad de vida a las personas con discapacidad.

Junto a, entre otras, la autotutela, el mandato preventivo, la legitimación activa de una persona para instar su propia incapacitación judicial y la consagración legal del contrato de alimentos, se rompe con la, hasta entonces, "cuasisagrada" intangibilidad de la legítima al permitirse gravar el tercio de legítima estricta con una sustitución fideicomisaria a favor de hijo o descendiente incapacitado judicialmente, introduciéndose, como novedad muy destacada (carente de antecedentes en nuestro Derecho), la figura jurídica del patrimonio protegido a favor de una persona con discapacidad, bien psíquica $(33 \%)$, bien física o sensorial $(65 \%)$, con independencia de que concurran o no en ella las causas de incapacitación judicial contempladas en el art. 200 C.c., presupuesto, en cambio, necesario, como acabamos de señalar, para gravar la legítima.

Basta, pues, a tenor de lo dispuesto por el art. 2 LPPD, con la incapacitación administrativa -no la judicial-, esto es, con acreditar suficientemente el grado de minusvalía legalmente establecido, a través de certificado reglamentario expedido por la Administración Pública correspondiente ${ }^{15}$ o de resolución judicial firme. ${ }^{16}$

Repárese en que la LPPD ha dado entrada en el Derecho civil a un término propio del Derecho Administrativo, "minusvalía”, y, conforme a ello, una valoración administrativa de carácter técnico ${ }^{17}$ va a tener, sorprendentemente, importantes efectos civiles, entre ellos, la atribución de la condición de representante legal a la persona nombrada administradora del patrimonio protegido constituido ex art. 5.7 LPPD, sin que, como estamos acostumbrados, exista intervención judicial alguna en su nombramiento, lo que es, cuanto menos, insólito.

${ }^{14}$ Leña Fernández, R.: "Posibilidades en materia sucesoria que, a favor de la persona con discapacidad, ofrece la Ley 41/2003”, en Los derechos de las personas con discapacidad, Vol. I Aspectos jurídicos, Laorden, J. (dir.) y Terreros, J.L. (coord.), CGPJ, Madrid, 2007, págs. 887-960, las califica, de manera enormemente gráfica, de "instrumentos que, al modo de rampas y ortopedias jurídicas, faciliten el tránsito de la persona con discapacidad por el mundo del derecho patrimonial” -pág. 891-.

${ }^{15}$ V. RD. 1971/1999, de 23 de diciembre sobre el procedimiento para el reconocimiento, declaración y calificación del grado de minusvalía, posteriormente modificado por el RD. 1169/2003, de 12 de septiembre y por la Disp. Fin. $3^{\text {a }}$ del RD. 290/2004, de 20 de febrero, por el que se regulan los enclaves laborales como medida de fomento del empleo de las personas con discapacidad. Para un estudio pormenorizado, vid. Salazar Murillo, J.: "Reconocimiento legal de la discapacidad", en Los derechos de las personas con discapacidad, Vol. I Aspectos jurídicos, Laorden, J. (dir.) y Terreros, J.L. (coord.), CGPJ, Madrid, 2007, págs. 735-777.

${ }^{16}$ Este último inciso del art. 2.3 de la LPPD que alude a la determinación judicial del grado de minusvalía no se alcanza a comprender, puesto que no se sabe de qué orden jurisdiccional debe provenir dicha resolución, si de la social -en vía de impugnación de una previa calificación administrativa de minusvalía-, o de la civil -si el juez que conoce de un procedimiento de incapacitación judicial tiene competencia para reconocer y graduar la discapacidad del demandado-.

${ }^{17}$ Concretamente, la resolución de la solicitud se funda en el reconocimiento por un Equipo de Valoración y Orientación (más conocido como EVO) del Centro Base correspondiente, el cual está formado por un médico, un psicólogo y un trabajador social y en la emisión de un dictamen técnico-facultativo en el que se expresa el porcentaje de la minusvalía mediante la aplicación de baremos contemplados en el RD. 1971/1999, concretamente en el Anexo I. 
Una primera lectura de la LPPD ofrece, sin duda alguna, una visión tremendamente positiva, entre otras razones, por introducir, por vez primera, en el Derecho civil, el término "discapacidad" (debidamente acreditada), el cual, colocándose junto al único existente hasta el momento, "incapacitación judicial", va a producir efectos civiles de gran trascendencia, ${ }^{18}$ además de por los instrumentos de tutela que contempla, provocando, de inmediato, una enorme sensación de alivio y satisfacción por haber logrado que el legislador civil se preocupara, por fin, de dar apoyo a muchas personas que, desde hacía tiempo, lo necesitaban y esperaban.

Sin embargo, un detenido análisis de tan bondadosa Ley, además de suscitar numerosos interrogantes como si su elaboración hubiera sido apresurada y estuviera aún inacabada, permite concluir que algunos de los mecanismos privados de protección económica de la discapacidad previstos en ella sólo están al alcance de unos pocos privilegiados, en concreto, de quienes gocen de un determinado estatus patrimonial en el cual, precisamente, no se encuentran la mayoría de los españoles que, en estos momentos, no pueden siquiera afrontar el pago del préstamo hipotecario a fin de mes. El legislador, si se nos permite la expresión, nos ha dejado con la miel en los labios.

Permítasenos omitir el análisis detallado de las herramientas jurídicas previstas en la LPPD, ${ }^{19}$ por resultar imposible en estas apretadas páginas, para centrarnos en el estudio del régimen jurídico de una de ellas, el patrimonio protegido, al hilo del cual plantearemos algunas de las concretas dudas, cuestiones o interrogantes que nos suscita el detenido examen del mismo (bien por indeterminación, bien porque hay aspectos regulados que, quizás, necesitarían una interpretación más flexible, o bien por lagunas), ${ }^{20}$ de las cuales, atrevidamente, avanzaremos, en un intento de suplir tales imprecisiones y vacíos, posibles soluciones - desde luego, discutibles-, a la espera de que nuestros Tribunales $^{21}$ o el legislador se pronuncien al respecto, quien, curiosamente, así lo ha hecho

18 Con anterioridad a la LPPD, la obtención del certificado administrativo de minusvalía era útil, exclusivamente, para acceder la persona y/o sus familiares a un amplio abanico de ayudas y beneficios sociales y económicos relativos a los programas y servicios de salud, educación, empleo, ocio, adquisición y adaptación de la vivienda, transporte, atención personal, prestaciones económicas (ej. pensiones no contributivas de jubilación e invalidez - con el $65 \%$ de minusvalía- y prestación familiar por hijo a cargo) y deducciones y exenciones fiscales (ej. deducciones en el IRPF y exención del Impuesto de matriculación y circulación en la compra de vehículos).

${ }^{19}$ Con algún pormenor, hemos tenido ocasión de estudiar éstas y otras medidas de tutela patrimonial en nuestro reciente trabajo La protección económica de la discapacidad, Bosch, Barcelona, 2009.

${ }^{20}$ Para Leña Fernández: "Posibilidades en materia sucesoria que, a favor de la persona con discapacidad, ofrece la Ley 41/2003", cit., "la Ley es muy imperfecta, con demasiadas imprecisiones, lagunas clamorosas y una evidente cortedad de alcance en las soluciones planteadas" -pág. 888-, pese a lo cual muestra una posición sumamente favorable: "aprecio en ella su apertura a espacios de libertad” -pág. 889-.

${ }^{21}$ En estos cinco años de vigencia de la LPPD, sólo hemos encontrado dos resoluciones judiciales que, tangencialmente, aluden a la LPPD: de un lado, el Auto de la AP de Cádiz, Sección 2a de 21 de marzo de 2005 (Westlaw Aranzadi JUR 2005, 144287), resolviendo acerca de la necesidad o no de la subasta pública para la venta de bienes de un incapacitado judicialmente, requisito éste suprimido por el art. 5 de la LPPD en relación a los bienes integrantes del patrimonio protegido de la persona con discapacidad y, de otro, la SAP de Navarra, Sección 3a , de 14 de junio de 2005 (Westlaw Aranzadi AC 2005, 1813), que, con ocasión de un caso de nombramiento de un tutor, se hace alusión a la Ley, en concreto, a la autotutela en previsión 
recientemente, pues acaba de ser aprobada la Ley 1/2009, de 25 de marzo, de reforma de la Ley de 8 de junio de 1957, sobre el Registro Civil, en materia de incapacitaciones, cargos tutelares y administradores de patrimonios protegidos, y de la Ley 41/2003, de 18 de noviembre, sobre protección patrimonial de las personas con discapacidad y de modificación del Código Civil, de la Ley de Enjuiciamiento Civil y de la normativa tributaria con esta finalidad, ${ }^{22}$ si bien muy escasas son las dudas que, generadas por la aplicación de la LPPD en sus cinco años de vigencia, pretende resolver, perdiéndose, en nuestra modesta opinión, una magnífica oportunidad para ello. ${ }^{23}$

\section{LA NUEVA FIGURA DEL PATRIMONIO PROTEGIDO ${ }^{24}$}

\subsection{Concepto, naturaleza y caracteres}

No cabe duda de que la novedad estrella de la LPPD es la figura del "patrimonio especialmente protegido", que es, según su Exposición de Motivos, el “objeto inmediato” de la misma, si bien, como hemos tenido ocasión de comprobar, aquélla no agota su contenido en la regulación del patrimonio protegido de las personas discapacitadas, pues contiene

de una futura incapacitación judicial, considerándose, curiosamente, que el deseo del incapaz manifestado en acto de vista oral es equivalente al expresado en documento notarial, además de prever, en su FJ $2^{\circ}$, la posibilidad de que en la misma escritura de autotutela se constituya un patrimonio protegido. Naturalmente, sí son, en cambio, numerosas las Resoluciones a consultas elevadas a la Dirección General de Tributos sobre la procedencia o no de las reducciones fiscales previstas por la LPPD para el patrimonio protegido por parte de quienes, no habiéndolo constituido cumpliendo los requisitos legales, pretenden beneficiarse de aquéllas.

${ }^{22}$ BOE núm. 73, de 26 de marzo de 2009.

${ }^{23}$ Puede decirse que el objetivo principal de dicha reforma legal es convertir el Registro Civil en un mecanismo fiable de publicidad que permita supervisar la efectiva aplicación de la normativa relativa a la incapacitación judicial de personas que no pueden gobernarse por sí mismas, así como facilitar la efectiva puesta en práctica de la figura del patrimonio protegido.

${ }^{24}$ V., entre una ya, afortunadamente, vasta bibliografía, Díaz Alabart, S./Alvarez Moreno, M ${ }^{\text {a }}$ T.: $L a$ protección jurídica de las personas con discapacidad: (estudios de la Ley 41/2003, de protección patrimonial de las personas con discapacidad), Ibermutuamur y Associació Catalana Naibu, 2004, en http://www.ibermutuamur. es/ibertalleres /web_juridica/ inicial.htm; López-Galiacho Perona, J.: “Aportaciones al estudio del llamado patrimonio protegido del discapacitado”, en Protección Jurídica y patrimonial de los discapacitados, coord. por D. Bello Janeiro, Escola Galega de Administración Pública, Santiago de Compostela, 2004, págs. 169209, y en RCDI, nº 687, enero-febrero 2005, págs. 31-60; Pérez De Ontiveros Baquero, C.: "Protección patrimonial de las personas mayores: el patrimonio especialmente protegido de las personas mayores con discapacidad como medida de protección de los mayores", Madrid, Portal Mayores, Informes Portal Mayores, $\mathrm{n}^{\circ}$ 42. [Fecha de publicación: 01/11/2005]; Herbosa Martínez, I.: "El patrimonio especial del discapacitado en la Ley 1/2003, de 18 de noviembre, de Protección Patrimonial del Discapacitado", en Actualidad Civil, 2005, págs. 1925-1954; Martín Romero, J. C.: "Del patrimonio y sus clases al patrimonio protegido del discapacitado”, en Revista Jurídica del Notariado, n 60, 2006, págs. 105-160; Amunátegui Rodríguez C. de: "La Constitución de un patrimonio protegido por las personas mayores inicialmente capaces en previsión de su futura pérdida de capacidad”, en Libro-Homenaje al Prof. Manuel Amorós Guardiola, Vol. I, 2006, págs. 77 110; Gallego Domínguez: “Aproximación al patrimonio protegido del discapacitado”, en Protección jurídica patrimonial de las personas con discapacidad, cit., págs. 113-180. 
otras importantes modificaciones legislativas encaminadas a crear, por primera vez, un estatuto patrimonial propio de estas personas.

La LPPD reconoce la posibilidad de constituir, en beneficio de la persona con discapacidad (incapacitada judicialmente o no, pero con el grado legal de minusvalía debidamente reconocido por certificado administrativo o resolución judicial firme), una masa patrimonial afecta expresamente a la satisfacción de sus "necesidades vitales" (lo que puede proporcionar cierta tranquilidad, jamás absoluta, a sus familiares) y sin personalidad jurídica propia.

Es un patrimonio que, en una rápida búsqueda de similitudes con otras figuras (lo cual puede resultar útil para solventar las posibles lagunas o vacíos legales existentes en torno a la nueva figura creada por la LPPD, acudiendo al régimen jurídico de la institución jurídica con la cual presente mayor analogía), se aproxima a la fundación ${ }^{25}$, la donación ${ }^{26}$ y al trust anglosajón. ${ }^{27}$

Según lo califica la propia Exposición de Motivos de la Ley, se trata, de un lado, de un "patrimonio de destino" en cuanto que las distintas aportaciones tienen como finalidad la satisfacción de las específicas necesidades vitales de su titular-beneficiario, y, de otro, "aislado" de su patrimonio personal. Al respecto, debemos realizar dos breves precisiones.

La primera, "patrimonio de destino" propiamente dicho no lo es, puesto que por tal se entiende aquel patrimonio que, transitoriamente, carece de titular y que, en atención al destino futuro, en espera de la concreción de su titular o, en su defecto, de su liquidación, el Ordenamiento Jurídico mantiene unido y sometido a una administración unitaria. Es el caso del nasciturus o concebido y no nacido, así como el de la herencia yacente. ${ }^{28}$

La segunda, es la gran incógnita de la LPPD, pues acerca de la responsabilidad por deudas del patrimonio protegido no se ha pronunciado (¿deliberadamente?) el legislador, pese a ser un aspecto práctico crucial del que depende, en buena medida, el éxito práctico de la figura. ¿Se trata de un patrimonio verdaderamente "aislado" o separado del patrimonio personal?: ¡Ojalá!, pero no, o si lo es, no de forma absoluta. Nos explicamos.

La Exposición de Motivos de la Ley establece que los bienes y derechos que forman el patrimonio protegido "se aíslan del resto del patrimonio personal de su titular-beneficiario,

${ }^{25}$ En ambas figuras existe el acto de dotación o aportación inicial al patrimonio protegido, las aportaciones posteriores, el destino de los bienes a la consecución de un fin y el control de la administración. Sin embargo, el interés general de la fundación se contrapone al interés particular del patrimonio protegido, que no goza de personalidad jurídica como sí, en cambio, la fundación.

${ }^{26}$ Entre las semejanzas existentes entre ambas, destacan, muy especialmente, la forma solemne que ha de revestir para su validez y su reversibilidad.

${ }^{27}$ V. Martín Santiesteban, S.: "El patrimonio de destino de la Ley de protección patrimonial de las personas con discapacidad: ¿un acercamiento al trust?”, en Actualidad Jurídica Aranzadi, 612, 2004, págs. 1-6, y Muñiz Espada, E.: "Trust y patrimonio protegido de las personas con discapacidad”, en Los patrimonios fiduciarios y el trust: III Congreso de Derecho civil Catalán, coord. por M. Garrido Melero y S. Nasarre Aznar, Marcial Pons, 2006, págs. 283-296.

${ }^{28}$ Así lo hace ver, con acierto, Gallego Domínguez: "Aproximación al patrimonio protegido del discapacitado”, en Protección jurídica patrimonial de las personas con discapacidad, cit., pág. 123. 
sometiéndolos a un régimen de administración y supervisión específico", pero omite toda alusión a la responsabilidad por deudas de tal patrimonio. De este modo, el patrimonio protegido, tal y como está configurado en la LPPD, está "especialmente protegido" sólo para su gestión y control, quedando "especialmente desprotegido" en relación a la responsabilidad por deudas de su titular, pues, ante el silencio legal, existe una evidente comunicación de responsabilidad por deudas ex art. 1911 C.c. entre ambos patrimonios, el protegido y el personal. ${ }^{29}$ En nuestra opinión, es necesario que el legislador afronte la expresa regulación de la responsabilidad patrimonial que corresponde al patrimonio protegido, considerando que la absoluta independencia del patrimonio protegido respecto del patrimonio personal es esencial para la eficaz protección de la persona con discapacidad. ${ }^{30}$

\subsection{Constitución}

\section{A) Aspectos personales (art. 3 LPPD)}

Para beneficiarse de la nueva figura del patrimonio especialmente protegido la persona debe tener discapacidad, esto es, estar afectada por una minusvalía psíquica igual o superior al $33 \%$ o por una minusvalía física y sensorial igual o superior al $65 \%$ reconocida. Por tanto, no es preciso que la persona haya sido incapacitada judicialmente, ni que se haya iniciado el procedimiento para ello, ni que siquiera concurran o no en ella las causas de incapacitación judicial contempladas en el art. 200 C.c. ${ }^{31}$ Así las cosas, y aunque pueda resultar extraño, con la Ley actual en la mano, ha de concluirse que una persona judicialmente incapacitada pero que no haya solicitado la declaración de minusvalía no puede ser titular de un patrimonio protegido.

Además, según se deduce de la LPPD, la discapacidad debe ser actual, de modo que no parece posible constituir un patrimonio protegido para el caso de una eventual discapacidad futura de la persona.

La LPPD prevé sólo la constitución de un patrimonio de titularidad individual, pero no contempla la posibilidad de la cotitularidad simultánea por dos o más beneficiarios. Conforme a ello, si nos representamos el supuesto de dos (o más) hijos con discapacidad a causa de una enfermedad degenerativa hereditaria, su padre/madre tendría que elegir a qué hijo designaría como beneficiario de un patrimonio protegido, o bien constituir dos

${ }^{29}$ Rotunda se muestra, al respecto, Moretón Sanz, Ma F.: "Protección civil de la discapacidad: patrimonio protegido y obras de accesibilidad en la Propiedad Horizontal”, en RCDI, núm. 687, 2005, pág. 77.

${ }^{30}$ Como apunta Pereña Vicente, M.: Asistencia y protección de las personas incapaces o con discapacidad: las soluciones del Derecho civil, Dykinson, Madrid, 2006, pág. 53, "especialmente preocupante se hace el problema de la comunicación de responsabilidad cuando la aportación se hace a través de un testamento, ya que el beneficiario, al aceptar la herencia, asume las deudas del causante, de las que responderá con todos sus bienes".

${ }^{31}$ Al respecto, señala Gallego Domínguez: “Aproximación al patrimonio protegido del discapacitado”, cit., pág. 127, "el criterio asumido por el legislador no es la protección de los incapacitados, sino el más amplio ámbito subjetivo de los discapacitados, partiendo de la realidad de que existe un amplio colectivo de discapacitados que no se encuentran incapacitados". 
distintos viéndose obligado/a a repartir los bienes entre ambos y a otorgar dos escrituras públicas (con los consiguientes gastos notariales y registrales, lo que sería absurdo) o bien, en caso de no disponer de recursos económicos suficientes, desistir de la idea para no causar un agravio comparativo. ¿No sería posible constituir un único patrimonio protegido a favor de ambos hijos? En caso afirmativo, ¿se trataría de una comunidad romana o germánica ${ }^{32}$ ?

Por otra parte, imaginemos el supuesto de un futuro aportante que no estuviese conforme con las reglas de administración establecidas por el constituyente de un patrimonio protegido, ¿podría constituir (o solicitar la constitución, en su caso) otro patrimonio protegido a favor del mismo beneficiario? Dicho de otro modo, ¿es posible que una persona sea beneficiaria de varios patrimonios protegidos constituidos a su favor? Nos inclinamos por una respuesta negativa, puesto que mantener dos o más patrimonios especiales con idéntico titular dominical es una situación excepcional que no es del agrado del Derecho, a menos que medie una causa que así lo justifique.

Otra cuestión: ¿es posible constituir un patrimonio protegido pero no realizar ninguna aportación al mismo hasta un momento ulterior? Pues la respuesta también ha de ser negativa, puesto que la Exposición de Motivos de la Ley afirma que "la constitución requiere, inexcusablemente, de una aportación originaria de bienes y derechos". Por consiguiente, el legislador parece exigir que el constituyente del patrimonio aporte en el mismo momento de su creación, sin que parezca permitirse una aportación prometida pero no realizada en el momento constitutivo, ${ }^{33}$ si bien ello sólo puede inferirse de la Ley, con absoluta claridad, en caso de constitución indirecta del patrimonio protegido (art. 3.2. LPPD), pero no en la directa.

Pasemos a conocer las dos formas de constitución del patrimonio protegido:

\section{Constitución directa:}

a) Constitución por la propia persona con discapacidad beneficiaria del patrimonio protegido (art. 3.1.a)

Ha de tener capacidad de obrar "suficiente". ${ }^{34}$ Éste es un término nuevo introducido por la LPPD en el Derecho civil, que requiere, en la mayoría de los casos, la plena capacidad de obrar. Cierto es que la introducción de este requisito por la LPPD deja al aire qué ha de entenderse por "suficiente", cuya determinación queda

32 Por la comunidad germánica se inclina Pereña Vicente: Asistencia y protección de las personas incapaces o con discapacidad: las soluciones del Derecho civil, cit., pág. 57, si bien es consciente de los innumerables inconvenientes que presenta dicha posibilidad.

33 De esta opinión, Gallego Domínguez: "Aproximación al patrimonio protegido del discapacitado”, cit., pág. 124: "no puede haber constitución de patrimonio sin dotación inicial”.

${ }^{34}$ V. Rivera Álvarez, J. Ma: "La capacidad de obrar suficiente en el patrimonio protegido de las personas con discapacidad”, en RDP, enero-febrero 2006, págs. 83-102. 
al buen criterio del aplicador del Derecho (Notario ${ }^{35}$ o Juez, en su caso). Sin embargo, la no exigencia de la plena capacidad de obrar reviste enorme importancia, pues permite que una persona con capacidad alterada o disminuida pueda ella misma intervenir en los procesos de constitución y aportaciones a su patrimonio protegido, lo cual se le hubiera impedido de haber exigido el legislador capacidad de obrar plena.

En el supuesto de que no se apreciase suficiente capacidad, puede instarse un procedimiento de incapacitación judicial para que su representante legal pueda crear un patrimonio protegido a su favor.

El menor de edad emancipado puede constituir un patrimonio protegido pero con las limitaciones impuestas por el art. 323 C.c., conforme al cual para tomar dinero a préstamo, constituir gravámenes y enajenar bienes inmuebles, establecimientos mercantiles o industriales y bienes muebles de extraordinario valor, no podrá hacerlo por sí solo sino contando con el consentimiento de sus padres o, en su defecto, de su curador, o de su cónyuge mayor de edad (art. 324 C.c.).

b) Constitución por padres, tutor (para lo cual debe contar con la autorización judicial ex art. $271.9^{\circ}$ C.c., curador o guardador de hecho de una persona con discapacidad psíquica cuando ésta no tenga capacidad de obrar suficiente, extremo éste que deberá ser probado o apreciado por el Notario autorizante de la escritura (art. 3.1.b) y c) LPPD).

El texto legal nos provoca un par de dudas:

- en relación al curador, sabemos que éste asiste o complementa la falta de capacidad de obrar, pero no sustituye jamás la voluntad de la persona. De acuerdo con ello, ¿no le otorga la LPPD facultades que son impropias?, ¿no debería exclusivamente limitarse a asistir al incapacitado judicialmente (que contase con capacidad de obrar suficiente y la sentencia no se lo impidiese) en la constitución del patrimonio protegido?, ¿qué hará el Notario autorizante en caso de existir discrepancia entre el curador y el curatelado?

- $\quad$ respecto a la constitución por el guardador de hecho de una persona con discapacidad psíquica: ¿por qué ha excluido el legislador a la persona con discapacidad física?; ¿cómo puede autorizar el Notario la constitución de un patrimonio por quien dice ser, pero no se tiene información alguna al respecto, guardador de hecho de alguien que no está incapacitado pero que padece una discapacidad psíquica?

35 En relación a la difícil tarea del Notario en orden a la valoración de la capacidad de la persona otorgante de un acto, vid. el interesante trabajo de Gómez Garzás, J.: "El juicio notarial de capacidad: especial referencia al deterioro cognitivo en la demencia tipo Alzheimer y otros trastornos afines", en $L a$ protección de las personas mayores, C. Lasarte Álvarez (dir.), Mª. F. Moretón Sanz y P. López Peláez (coords.), cit., págs. 216-233. 


\section{Constitución indirecta:}

La LPPD reconoce, en su art. 3.2, legitimación activa indirecta (no, por tanto, para constituir directamente el patrimonio protegido, pero sí para tener "iniciativa constituyente", esto es, ser promotores para que otros lo constituyan) a cualquier persona:

- "con interés legítimo" (concepto indeterminado que puede abarcar tanto a familiares -abuelos, hijos, nietos de la persona con discapacidad que no ostenten ningún cargo tutelar- como a personas extrañas) para que solicite la constitución del patrimonio protegido a los padres, tutores y curadores (se omite al guardador de hecho) $\mathrm{y}$, en caso de negativa injustificada de los padres y tutores (no, curiosamente, del curador-que sí aparece en relación a las aportaciones por terceros ex art. 4.2- ni del guardador de hecho) podrá acudir al fiscal y éste instará del juez lo que proceda en un procedimiento de jurisdicción voluntaria (aún por legislar tras la retirada por el Gobierno del Proyecto de Ley 121/000109 Jurisdicción Voluntaria ${ }^{36}$ para facilitar y agilizar la tutela y garantía de los derechos de la persona y en materia civil y mercantil ${ }^{37}$ el día 24 de octubre de 2007 , fecha fijada para la votación del mismo en el Pleno del Senado). Al respecto, nos preguntamos: si el patrimonio protegido sólo reporta beneficios a la persona con discapacidad, ¿en qué puede basarse un justificado rechazo por parte de los representantes legales a la constitución de un patrimonio protegido a su favor promovida por un tercero?

- Que ofrezca una aportación de bienes y derechos adecuados "suficiente" para constituir el patrimonio protegido. Dicha "suficiencia" de la aportación no es exigida por la LPPD en el supuesto de constitución directa del patrimonio. ¿Cuánto es "suficiente"?, o lo que es lo mismo, ¿qué es "insuficiente"?, ¿no basta con cualquier aportación?, ¿por qué no, si por mínima que fuese, no perjudicaría a la persona con discapacidad, pudiendo ser, posteriormente, aumentada por cualquier persona? ${ }^{38}$

- El legislador no se plantea la posibilidad de que la persona con discapacidad con capacidad de obrar suficiente no acepte la iniciativa constitutiva de un tercero (sí lo prevé, en cambio, para las aportaciones de ampliación del patrimonio), cuestión que deja sin revolver. No creemos que, en tal caso, pueda acudir el tercero al fiscal y éste al juez, debiéndose respetar la voluntad de la persona con discapacidad, de acuerdo con el principio general de autonomía personal y libre desarrollo de la personalidad que informa nuestro Ordenamiento jurídico (art. 10.1 CE).

${ }^{36}$ En cumplimiento de lo dispuesto por la Disp. Final $18^{\mathrm{a}}$ de la LEC-2000, aunque con un considerable retraso.

${ }^{37}$ Publicado en el Boletín Oficial de las Cortes Generales, Congreso de los Diputados, Serie A, de 27 de octubre de 2006 (http://www.congreso.es/public_oficiales/L8/CONG/BOCG/A/A_109-01.PDF).

38 Precisamente, en la tramitación del Proyecto de Ley, el Grupo Parlamentario Socialista presentó en el Congreso la enmienda núm. 42 proponiendo la supresión de un mínimo para la aportación inicial, al considerar que "no es conveniente establecer limitaciones a la hora de constituir el patrimonio protegido. Debe tenerse en cuenta que el patrimonio protegido inicialmente constituido, aunque en principio sea de escasa cuantía, puede ser incrementado mediante aportaciones sucesivas”. 
En un procedimiento de incapacitación judicial, ¿podría el propio juez, de oficio, ordenar la constitución del patrimonio protegido a favor del incapacitado, siempre y cuando éste acredite el grado de minusvalía exigido por el art. 2.2 LPPD? Nos decantamos por una respuesta positiva, pero consideramos que, para disipar cualquier duda al respecto, debería incluirse explícitamente en la LPPD entre las personas legitimadas para la constitución del patrimonio protegido.

B) Aspectos reales (art. 4.2 y 4.3 LPPD)

Tanto la primera aportación de constitución del patrimonio protegido como las sucesivas pueden consistir en dinero, depósitos en cuentas corrientes, seguros, alimentos o rentas vitalicias, bienes muebles o inmuebles, derechos reales (p. ej. un usufructo), títulos, acciones, emisiones de deuda pública, etc. Naturalmente, formarán asimismo parte del patrimonio los frutos, productos y rendimientos de tales bienes y derechos que lo integren.

En el caso de las aportaciones posteriores a un patrimonio protegido ya constituido, el legislador parece estar pensando en la hipótesis de que las realicen personas distintas al propio titular-beneficiario del mismo, quien también puede aportar.

De acuerdo con ello, las aportaciones pueden ser:

- transmisiones a título gratuito inter vivos (donación, en cuyo caso, recuérdese, ésta no puede comprender bienes futuros ex art. 635 C.c.) o mortis causa (legado por disposición testamentaria) o

- simple afecciones, adscripciones o trasvases patrimoniales cuando se trata de aportaciones realizadas por el propio titular-beneficiario, pues "nadie puede transmitirse bienes a sí mismo". En tal caso, dado que no puede hablarse, en rigor, de transmisión o traspaso a otra persona ( $y$, sin embargo, ha de cumplimentarse la forma pública ad solemnitatem exigida por la Ley), ¿podría aportarse a sí mismo derechos personalísimos o intransmisibles (p. ej. derecho de uso y habitación)? ${ }^{39}$

Las aportaciones realizadas inter vivos quedan sujetas a las normas de revocación de las donaciones, son reducibles por inoficiosidad y rescindibles por fraude de acreedores (arts. 618 y ss. C.c.), tal y como establece la LPPD en su Exposición de Motivos, pues ésta no modifica en nada las reglas generales del C.c. o, en su caso, de los Derechos civiles autonómicos, relativas a los distintos actos y negocios jurídicos.

La Ley exige, en su art. 4.2, que cuando el tercero promotor de la constitución del patrimonio protegido quiera, posteriormente, hacer una aportación, ha de contar con el consentimiento de la persona con discapacidad o, si no tuviera capacidad de obrar suficiente, con el de sus padres, tutores o curadores. El consentimiento del titular-beneficiario del patrimonio protegido lo consideramos procedente y ha de respetarse en todo caso, pero respecto al de los padres, tutores o curadores (de nuevo, otorgándosele a éste

${ }^{39}$ Por una respuesta afirmativa se inclina Gallego Domínguez: “Aproximación al patrimonio protegido del discapacitado”, en Protección jurídica patrimonial de las personas con discapacidad, cit., pág. 145. 
facultades que no le son propias), ¿no es excesivo? Cierto es que la propia Ley prevé una solución en caso de oposición injustificada: acudir al fiscal (obviamente imposible por el propio tercero aportante, si la aportación la ha realizado mortis causa), ${ }^{40}$ quien instará del juez lo que proceda atendiendo al interés de la persona con discapacidad. Pero, ¿no es más excesivo aún, sobre todo si, para solicitar la constitución del patrimonio y ante la disconformidad de los padres o tutor, ya se vio obligado a acudir, a través del Fiscal, a la autoridad judicial, a la que tendrá que recurrir ahora de nuevo? Es indudable que el sistema de aportaciones al patrimonio debería facilitarse el máximo posible; de lo contrario, con tantos obstáculos, ¿qué tercero querrá aportar?

Por otra parte, el consentimiento legalmente exigido, ¿debe cumplir algún requisito de forma (p. ej. escritura pública como en el caso de aceptación de donación de un bien inmueble ex art. 633 C.c.)?

Tales aportaciones realizadas por persona con interés legítimo deben siempre realizarse a título gratuito y no pueden someterse a término o plazo (art. 4.2 LPPD).

En relación surgen algunas cuestiones:

- Si la LPPD sólo menciona el plazo, ¿es posible someter las aportaciones a condición (p. ej. ser declarado judicialmente incapacitado o no internar al titular-beneficiario en ningún centro especializado)? ${ }^{41}$ ¿y a modo (p. ej. atender a determinada persona con las rentas del patrimonio protegido o pagar una deuda del aportante, siempre que la atribución supere el valor de la carga, como sucede en la donación modal)? Nada dice el legislador, de manera que lo que no está expresamente prohibido, está permitido. Esta opinión, además, puede fundarse, en relación a la carga modal, en dos argumentos: de un lado, el modo no transforma la aportación en onerosa, sino tan sólo deja una puerta abierta a la revocación en caso de incumplimiento por parte del beneficiado; de otro, la propia Ley (art. 4.3) permite la reversibilidad de la aportación, a la que ha de darse el destino previsto por el tercero, lo que no constituye más que una aportación con cláusula modal, si bien sólo para el caso de extinción del patrimonio protegido.

- Por otra parte, la LPPD prohíbe el sometimiento a plazo de las aportaciones de terceros, pero, y las realizadas por el propio beneficiario, ¿pueden someterse a término, modo o condición o tienen, por el contrario, que ser puras?

- Si lo que el legislador quiere evitar son aportaciones a término o resolubles, ¿cómo es posible aportar al patrimonio protegido derechos temporales, como un usufructo, una opción de compra o un derecho arrendaticio?

- $\quad$ Si el tercero aportante estipulase, en contra de la prohibición legal, una aportación a plazo, siendo éste la muerte del titular-beneficio del patrimonio, ¿sería válida?

${ }^{40}$ En tal supuesto, como apunta Gallego Domínguez: Op. cit., pág. 138, deberá acudir al Ministerio Fiscal el albacea testamentario (art. 902.3 C.c.) o bien los herederos.

41 Pereña Vicente: Asistencia y protección de las personas incapaces o con discapacidad: las soluciones del Derecho civil, cit., pág. 81, entiende admisible la condición suspensiva pero no la resolutoria, "porque ello supondría una alteración de la regla que impide que los bienes salgan del patrimonio protegido si no es por extinción del mismo". 
Consideramos que sí, puesto que dicho término final ya está fijado ex lege (art. 6.1 LPPD).

Otro dato importante es que el patrimonio protegido queda inmediata y directamente vinculado a las "necesidades vitales" (así como al mantenimiento de su productividad, ex art. 5.4. LPPD), el cual es un concepto jurídico indeterminado que exige concreción judicial según las circunstancias del caso concreto, pues los cuidados y atenciones pueden llegar a ser muy diversos (p. ej. ¿es "necesidad vital" contratar a un/a cuidador/a las 24 horas del día para atender a la persona con discapacidad? ¿y satisfacer determinadas aficiones como un viaje turístico a un lugar lejano? ¿y sufragar la adquisición de una vivienda?). Más allá de la manutención, habitación, asistencia médica y educación, ¿no pueden considerarse "necesidades vitales" las de bienestar psíquico de la persona con discapacidad? Por otra parte, según creemos, el legislador está pensando exclusivamente en las "necesidades vitales" del titular-beneficiario del patrimonio protegido, pero y si éste tuviera personas a su cargo, ¿podría también satisfacer sus "necesidades vitales" con los bienes integrantes de su patrimonio protegido?

Por último, la LPPD, en su art. 4.3, concede la posibilidad de que el aportante (ya sea un tercero, ya los padres, tutores o curadores) pueda establecer el destino que a los bienes o derechos aportados deba darse una vez extinguido el patrimonio protegido, determinando que tales bienes o derechos reviertan en el aportante o sus herederos o dándoles cualquier otro destino lícito que estime oportuno (p. ej. que se entreguen a una fundación tutelar o a otra persona con discapacidad). Sin embargo, esta facultad del aportante tiene un límite, ya que la salida del bien o derecho aportado del patrimonio protegido tan sólo podrá producirse por extinción de éste, lo que elimina la posibilidad de afecciones de bienes y derechos a término, salvo que éste sea el fallecimiento del titular-beneficiario del patrimonio.

\section{C) Aspectos formales (arts. 3.3 y 4.1 LPPD)}

La Ley impone tanto a la hora de constituir el patrimonio protegido como en las aportaciones ulteriores de aumento del mismo la forma ad solemnitatem en documento público (escritura pública y testamento abierto) o mediante resolución judicial en el supuesto de autorización por el Juez antes mencionado (art. 3.2). ${ }^{42}$

Ello quiere decir que no es posible constituir un patrimonio protegido ni realizar aportaciones al mismo en otra forma distinta, ni verbal, ni escrita, no siendo, por tanto, válido un documento privado (que, en cambio, sí lo es para la donación de bienes muebles ex art. 632 C.c., la cual, si fuera la forma elegida para realizar una aportación a un patrimonio protegido, tendría, posteriormente, que recogerse en documento público notarial).

42 Gallego Domínguez: “Aproximación al patrimonio protegido del discapacitado”, cit. pág. 147, subraya el error en el cual incurre el legislador al contraponer documento público a resolución judicial, como si ésta no fuera un documento público. 
Por tanto, a efectos de validez (por tanto, no meramente probatorios ni de publicidad), sólo puede revestir forma pública notarial (la SAP de Navarra, Sección $3^{\text {a }}$, de 14 de junio de 2005, 43 en su FJ $2^{\circ}$, apunta la posibilidad de aprovechar la misma escritura pública para la autotutela y para la constitución de un patrimonio protegido) o resolución judicial.

Consideramos realmente excesiva dicha rigidez formal, no tanto para el acto constitutivo del patrimonio protegido como para las aportaciones realizadas posteriormente al mismo para aumentarlo, lo cual puede motivar la reticencia a llevarlas a cabo, provocando un efecto desincentivador justamente contrario al pretendido por la LPPD. Por ejemplo, piénsese en el caso de aportaciones dinerarias periódicas (p. ej. mediante ingresos en cuenta bancaria); cada vez que se realice una es preciso ir a la Notaría y otorgar escritura pública o, incluso, en caso de negativa injustificada a las aportaciones, al Fiscal y éste al Juez. La fijación de tantas trabas formales choca, sin lugar a dudas, con la finalidad tuitiva de los intereses patrimoniales de la persona con discapacidad que persigue la LPPD. Tal vez el legislador debió haber limitado la forma solemne a las aportaciones sucesivas no dinerarias.

El documento público notarial o la resolución judicial ha de tener un contenido mínimo:

- $\quad$ El inventario de los bienes y derechos que inicialmente constituyan el patrimonio protegido.

- La determinación de las reglas de administración y, en su caso, de fiscalización, incluyendo los procedimientos de designación de las personas que hayan de integrar los órganos de administración o, en su caso, de fiscalización, todo ello conforme a lo establecido en el art. 5 LPPD. Resulta conveniente anticiparse y tener todo bien atado, en previsión de posibles situaciones que pueden eventualmente darse (p. ej. pérdida de capacidad de obrar del beneficiario-constituyente, remoción del cargo de administrador por mala gestión, etc.) y a las cuales se aplicarían las reglas expresamente consignadas en el documento con carácter preferente a lo que, en su caso, decidiese el juez para remediarlas.

- Cualquier otra disposición que se considere oportuna respecto a la administración o conservación del mismo.

La reciente Ley 1/2009, de 25 de marzo, ha añadido un párrafo al art. 3.3 LPPD, incorporando una previsión adicional referida a la comunicación telemática de la constitución del patrimonio protegido y de las aportaciones al mismo con el objetivo de conseguir un mayor control. ${ }^{44}$

43 Westlaw Aranzadi, AC 2005, 1813.

${ }^{44}$ Dicho párrafo presenta el siguiente tenor literal: "Los notarios comunicarán inmediatamente la constitución y contenido de un patrimonio protegido por ellos autorizado al fiscal de la circunscripción correspondiente al domicilio de la persona con discapacidad, mediante firma electrónica avanzada. Igual remisión efectuarán de las escrituras relativas a las aportaciones de toda clase, que se realicen con posterioridad a su constitución.

El fiscal que reciba la comunicación de la constitución de un patrimonio protegido y no se considere competente para su fiscalización lo remitirá al fiscal que designe el Fiscal General del Estado, de acuerdo con su Estatuto Orgánico". 


\subsection{Administración del patrimonio (art. 5 LPPD) $)^{45}$}

Ante todo debe precisarse que el término "administración" lo emplea la LPPD, en su art. 5, en sentido amplio, comprensivo también de los actos de disposición o enajenación, según precisa en su propia EM.

En principio, todos los bienes y derechos, cualquiera que sea su procedencia, se sujetan al régimen de administración establecido por el constituyente del patrimonio, el cual tiene plenas facultades para establecer las reglas de administración que considere oportunas, favoreciéndose, de esta forma, que la administración pueda corresponder a entidades sin ánimo de lucro especializadas en la atención a las personas con discapacidad, si bien es preciso distinguir:

- $\quad$ si el constituyente del patrimonio protegido es el propio beneficiario del mismo, al contar con la capacidad de obrar suficiente para ello, la administración del patrimonio se sujeta a las reglas que libremente establezca en el documento público constitutivo.

- en los demás casos, las reglas de administración establecidas en el documento público de constitución (por tanto, no parece que pueda establecerlas un aportante posterior) deben prever que se requiera autorización judicial en los mismos supuestos que el tutor la requiere respecto de los bienes del tutelado conforme a la legislación civil (estatal o autonómica), si bien se permite que el juez pueda flexibilizar este régimen cuando las circunstancias concurrentes en el caso concreto así lo hicieran conveniente (cuando el beneficiario tenga capacidad de obrar suficiente o en los supuestos contemplados en el art. 5.3 LPPD).

En ningún caso es necesaria la subasta pública para la enajenación de los bienes o derechos integrantes del patrimonio protegido ex art. 5.2 LPPD (la SAP de Cantabria, Sección $2^{\mathrm{a}}$, de 13 de noviembre de $2007,{ }^{46}$ considera esta norma directamente aplicable a la venta de bienes de incapacitados "sea cual sea el régimen peculiar del patrimonio de éste, puesto que, en suma, en el caso contrario estaríamos discriminando desfavorablemente a los discapacitados o incapacitados cuyos guardadores, tutores o ejercientes de la curatela no bubieran adoptado las medidas precisas para la constitución del patrimonio separado a que se refiere la Ley 41/2003, sin que en nada difiera la naturaleza y fundamento de la venta de bienes de personas discapacitadas de la de los bienes de personas judicialmente incapacitadas, de modo que, si para aquéllas es beneficioso el que se prescinda de la pública subastas en la enajenación de sus bienes, también habrá de serlo para éstas, si bien se estima necesario que el Órgano Jurisdiccional adopte las medidas de vigilancia y control que, en relación con la venta, estime adecuadas y pertinentes en beneficio del tutelado de conformidad con lo establecido en el artículo 233 del Código Civil“, FJ $\left.1^{\circ}\right)$.

${ }^{45}$ V. Sánchez-Calero Arribas, B.: "La administración y la supervisión del patrimonio protegido creado por la ley 41/2003, de 18 de noviembre, de protección patrimonial de las personas con discapacidad", en RCDI, No 695, 2006, págs. 1057-1100.

46 Westlaw Aranzadi, AC 2008, 277. 
Dada la disparidad de criterios detectados en la práctica en cuanto a qué se entiende por "actos de disposición" de determinados bienes integrantes del patrimonio, la nueva Ley $1 / 2009$, de 25 de marzo, introduce un nuevo párrafo en el art. 5.2 de la Ley con la siguiente redacción: "En todo caso, y en consonancia con la finalidad propia de los patrimonios protegidos de satisfacción de las necesidades vitales de sus titulares, con los mismos bienes y derechos en él integrados, así como con sus frutos, productos y rendimientos, no se considerarán actos de disposición el gasto de dinero y el consumo de bienes fungibles integrados en el patrimonio protegido, cuando se hagan para atender las necesidades vitales de la persona beneficiaria".

El administrador del patrimonio protegido puede ser el propio beneficiario, su representante legal en caso de estar judicialmente incapacitado o bien una persona distinta, en cuyo caso, según establece la LPPD en su art. 5.7, "tendrá la condición de representante legal" para todos los actos de administración de los bienes y derechos integrantes del patrimonio protegido, y no requerirá el concurso de los padres o tutor para su validez y eficacia.

De acuerdo con ello, nos podemos encontrar a una persona designada en la escritura pública de constitución del patrimonio protegido a quien se le confía la administración del mismo sin intervención judicial alguna, tal y como el C.c. exige en los casos de nombramiento de representante legal (p. ej. tutor, defensor judicial o el del ausente). A pesar de parecerse más a un representante voluntario designado por el propio beneficiario que a un representante legal, ${ }^{47}$ la Ley, sorprendentemente, le concede dicha condición, que, en última instancia, se sustenta sobre un documento administrativo (no judicial) de minusvalía. Dicha representación legal ha de hacerse contar en el Registro civil ex art. 8.1 LPPD (en su nueva redacción dada por la Ley 1/2009).

La administración del patrimonio protegido puede recaer tanto sobre una persona física como jurídica. Respecto a ésta señalamos que el art. 242 C.c., en relación a la tutela, establece: "podrán ser también tutores las personas jurídicas que no tengan finalidad lucrativa y entre cuyos fines figure la protección de menores e incapacitados". ¿Y las personas con discapacidad que no hayan sido declaradas judicialmente incapaces? Sin duda, el legislador de 2003 ha padecido un lapsus u olvido, pues debió haber modificado la redacción del precepto añadiendo, entre los fines, la protección de las personas con discapacidad. Dicho desajuste debería ser subsanado para conseguir una adecuada concordancia legislativa.

\subsection{Control y supervisión (art. 7 LPPD)}

Conforme a la Exposición de Motivos de la LPPD, el constituyente puede establecer las reglas de supervisión y fiscalización de la administración del patrimonio que considere oportunas, nombrando, si así lo desea para su mayor tranquilidad, un órgano fiscalizador (p. ej. que pida al administrador informes previos a determinadas actuaciones).

${ }^{47}$ Precisión que, con acierto, realiza Pereña Vicente: Asistencia y protección de las personas incapaces o con discapacidad: las soluciones del Derecho civil, cit., pág. 96. 
Junto a ellas, la supervisión institucional del patrimonio protegido corresponde al Ministerio Fiscal, respecto del cual el art. 7 LPPD prevé dos tipos de actuaciones, a saber:

- Una supervisión permanente y general de la administración del patrimonio protegido, a través de la información que, periódicamente, el administrador distinto del beneficiario y de sus padres debe remitirle en cuanto a su gestión, la cual debe justificar documentalmente.

- Una supervisión esporádica y concreta, ya que cuando las circunstancias concurrentes en un momento determinado lo hicieran preciso, el Ministerio Fiscal puede solicitar del juez la adopción de cualquier medida que se estime pertinente en beneficio de la persona con discapacidad. A estos efectos, el Ministerio Fiscal puede actuar tanto de oficio como a solicitud de cualquier persona, y será oído en todas las actuaciones judiciales que afecten al patrimonio protegido, aunque no sean instadas por él.

Por otro lado, la LPPD crea la Comisión de Protección Patrimonial de las Personas con Discapacidad, adscrita al Ministerio de Trabajo y Asuntos Sociales, en la que participarán representantes de la asociación más representativa de los diferentes tipos de discapacidad y cuya función básica es ser un órgano externo de apoyo, auxilio y asesoramiento del Ministerio Fiscal en el ejercicio de sus funciones, sin perjuicio de las demás que reglamentariamente pudieran atribuírsele. La reciente Ley 1/2009, de 25 de marzo, prevé la presencia, en todo caso, del Ministerio Fiscal en dicha Comisión. ${ }^{48}$

\subsection{Extinción (art. 6 LPPD)}

La LPPD regula, en su art. 6, la extinción del patrimonio protegido, que se producirá, bien por fallecimiento (muerte o declaración firme de fallecimiento) del beneficiario, pasando el patrimonio a formar parte de su herencia, o bien por dejar de padecer una minusvalía en los grados establecidos por la Ley. En este último caso, dada la temporalidad que caracteriza a todo patrimonio de destino ante la inexistencia de la causa que justifica la separación, se integrará automáticamente en el personal, pero entendemos que no por entero, sino lo que hubiese quedado tras liquidar las deudas contraídas en virtud de las "necesidades vitales" y destinar las aportaciones a los fines queridos por sus aportantes conforme a la reversibilidad prevista en el art. 4.3. LPPD. Si ello fuera material o jurídicamente imposible, se les dará otra finalidad, lo más análoga y conforme posible a la voluntad del aportante (a semejanza de la conmutación modal regulada por el art. 798, pfo. $1^{\circ}$ C.c., a la que se refiere la propia Exposición de Motivos de la Ley y atendiendo, si procede, a la naturaleza de los bienes y derechos que integran el patrimonio protegido en el momento de su extinción y en proporción a las diferentes aportaciones).

${ }^{48}$ El RD. 177/2004, de 30 de enero, modificado por el RD. 2270/2004, de 3 de diciembre, ha regulado su composición, funcionamiento y funciones de dicha Comisión. 
Otra causa extintiva es la contemplada por el art. 7.1 LPPD, por la cual, por decisión judicial, se decrete el fin del patrimonio protegido en beneficio de la persona con discapacidad.

También podría pensarse en la terminación del patrimonio protegido que quedase vacío de contenido por desaparición de los bienes y derechos que lo componen sin ser éstos sustituidos por otros por subrogación real (p. ej. una indemnización procedente de un seguro en lugar del bien asegurado) por distintas circunstancias (p. ej. destrucción de los bienes integrantes, impugnación judicial de aportaciones por simulación o fraude, pago de deudas que absorban todo el activo patrimonial, etc).

Como puede vislumbrarse, las causas legalmente previstas son, exclusivamente, de extinción involuntaria del patrimonio protegido. Pero, si es posible que la propia persona con discapacidad constituya voluntariamente el patrimonio protegido, ¿por qué no es posible también su voluntaria extinción?, ¿qué inconvenientes existirían al respecto?

\subsection{Constancia registral (art. 8 LPPD)}

La LPPD, en su art. 8 (precepto que ha recibido nueva redacción por la Ley 1/2009, de 25 de marzo), contempla dos importantes medidas de publicidad registral:

$1^{\mathrm{a}}$. Constancia en el Registro Civil de la representación legal que el administrador del patrimonio protegido ostenta cuando no se trata ni del propio beneficiario ni de sus padres, tutores o curadores.

$2^{a}$. En el Registro de la Propiedad ha de constar la condición de un bien o derecho real inscrito como integrante de un patrimonio protegido mediante inscripción. El legislador de 2003 presupone que siempre existe transmisión de bienes que da lugar a la inscripción, pero no se plantea el supuesto de la constitución o aportaciones realizadas al patrimonio por el propio titular-beneficiario, en cuyo caso no existe transmisión alguna. Con el fin de colmar tal laguna, la Ley 1/2009 establece al respecto: "Si el bien o derecho ya figurase inscrito con anterioridad a favor de la persona con discapacidad se hará constar su adscripción o incorporación al patrimonio protegido por medio de nota marginal".

La nueva Ley de 2009 también dispone que "La publicidad registral de los asientos a que se refiere este precepto se deberá realizar, en los términos que reglamentariamente se determinen, con pleno respeto a los derechos de la intimidad personal y familiar y a la normativa sobre protección de datos de carácter personal".

\subsection{Valoración personal}

Después de cinco años de rodaje del patrimonio protegido, debemos concluir que, pese a su magnífica potencialidad, es un instrumento de planificación económica, desafortunadamente, infrautilizado en la práctica (la falta de litigiosidad en nuestros Tribunales es buena prueba de ello).

Ello es debido a la inexistente separación radical, en cuanto a la responsabilidad por deudas, entre el patrimonio protegido y el personal, a lo que ha contribuido, sin duda, un tratamiento fiscal deficiente, que impide que el patrimonio protegido se convierta en una atractiva fórmula de ahorro y, por tanto, pueda cumplir su finalidad tuitiva. 
Otra causa por la que no se constituyen más patrimonios protegidos radica en que los familiares de los posibles beneficiarios, en muchas ocasiones, no tienen noticia alguna de la existencia de esta figura. Es indispensable una mayor información y difusión de su contenido, eficacia y utilidad (muy especialmente, cuando cada vez son mayores las dudas acerca de la solvencia financiera pública) como instrumento jurídico de protección y seguridad de las personas con discapacidad.

Por último, es indiscutible que para constituir un patrimonio protegido es presupuesto básico tener patrimonio. La LPPD está destinada a familias de una determinada posición económica, o bien a aquellas que, pese a tener un patrimonio reducido, son capaces de realizar ese esfuerzo, si bien, dado el progresivo endeudamiento que la familia media española está, en la actualidad, padeciendo, sumado a la falta de incentivos fiscales más beneficiosos, serán muy pocas las que, en estos momentos, puedan plantearse crear un patrimonio protegido en beneficio de un ser querido con discapacidad.

\section{BIBLIOGRAFÍA}

Alonso Pérez, M., Martínez Gallego E. Ma y Reguero Celada, J. (coords.): Protección jurídica de los mayores, La Ley, Madrid, 2004.

Alvarez Lata, N./Seoane Rodríguez, J. A.: Derecho y retraso mental. Hacia un estatuto jurídico de la persona con retraso mental, A Coruña, 1999.

Amunátegui Rodríguez C. de: "La Constitución de un patrimonio protegido por las personas mayores inicialmente capaces en previsión de su futura pérdida de capacidad", en LibroHomenaje al Prof. Manuel Amorós Guardiola, Vol. I, 2006, págs. 77-110.

Cabra De Luna, M. A./Bariffi, F./Palacios, A.: Derechos humanos de las personas con discapacidad: la Convención Internacional de las Naciones Unidas, Colección La Llave, Madrid, 2007.

De Lorenzo, R./Palacios, A.: "Discapacidad, derechos fundamentales y protección constitucional”, en Los derechos de las personas con discapacidad, Vol. I Aspectos jurídicos, Laorden, J. (dir.) y Terreros, J.L. (coord.), CGPJ, Madrid, 2007, págs. 63-79.

Díaz Alabart, S./ Alvarez Moreno, Mª . T.: La protección jurídica de las personas con discapacidad: (estudios de la Ley 41/2003, de protección patrimonial de las personas con discapacidad), Ibermutuamur y Associació Catalana Naibu, 2004, en http://www.ibermutuamur.es/ibertalleres/web_juridica/ inicial.htm.

Gallego Domínguez, I.: “Aproximación al patrimonio protegido del discapacitado”, en Protección jurídica patrimonial de las personas con discapacidad, coord. por J. Pérez De Vargas, La Ley-Actualidad, Madrid, 2007, págs. 113-180.

Gómez GARZÁs, J.: "El juicio notarial de capacidad: especial referencia al deterioro cognitivo en la demencia tipo Alzheimer y otros trastornos afines", en La protección de las personas mayores, C. Lasarte Álvarez (dir.), Mª. F. Moretón Sanz y P. López Peláez (coords.), cit., págs. 216-233.

Herbosa Martínez, I.: "El patrimonio especial del discapacitado en la Ley 1/2003, de 18 de noviembre, de Protección Patrimonial del Discapacitado", en Actualidad Civil, 2005, págs. 1925-1954.

Jiménez Lara, A./Huete García: A.: Los discapacitados en España: Datos estadísticos. Aproximación desde la Encuesta sobre Discapacidades, Deficiencias y Estado de Salud de 1999, Ministerio de Trabajo y Asuntos Sociales, Real Patronato sobre Discapacidad, Madrid, 2003. 
Lasarte Álvarez, C., Moretón Sanz, Ma F., y López Peláez, P. (coords.): La protección de las personas mayores, Tecnos, Madrid, 2007.

LeÑa Fernández, R.: "Posibilidades en materia sucesoria que, a favor de la persona con discapacidad, ofrece la Ley 41/2003", en Los derechos de las personas con discapacidad, Vol. I Aspectos jurídicos, Laorden, J. (dir.) y Terreros, J.L. (coord.), CGPJ, Madrid, 2007, págs. 887-960.

López-Galiacho Perona, J.: “Aportaciones al estudio del llamado patrimonio protegido del discapacitado”, en Protección Jurídica y patrimonial de los discapacitados, coord. por D. Bello Janeiro, Escola Galega de Administración Pública, Santiago de Compostela, 2004, págs. 169-209 y en $R C D I, \mathrm{n}^{\circ} 687$, enero-febrero 2005, págs. 31-60.

Martín Romero, J. C.: "Del patrimonio y sus clases al patrimonio protegido del discapacitado", en Revista Jurídica del Notariado, no 60, 2006, págs. 105-160.

Martín Santiesteban, S.: "El patrimonio de destino de la Ley de protección patrimonial de las personas con discapacidad: ¿un acercamiento al trust?”, en Actualidad Jurídica Aranzadi, 612, 2004, págs. 1-6.

Moretón SAnZ, Ma F.: "Protección civil de la discapacidad: patrimonio protegido y obras de accesibilidad en la Propiedad Horizontal”, en RCDI, núm. 687, 2005, págs. 61-115.

MuÑIz EsPadA, E.: "Trust y patrimonio protegido de las personas con discapacidad", en Los patrimonios fiduciarios y el trust: III Congreso de Derecho civil Catalán, coord. por M. Garrido Melero y S. Nasarre Aznar, Marcial Pons, 2006, págs. 283-296.

Pereña Vicente, M.: Asistencia y protección de las personas incapaces o con discapacidad: las soluciones del Derecho civil, Dykinson, Madrid, 2006.

Pérez De Ontiveros Baquero, C.: "Protección patrimonial de las personas mayores: el patrimonio especialmente protegido de las personas mayores con discapacidad como medida de protección de los mayores", Madrid, Portal Mayores, Informes Portal Mayores, $n^{\circ} 42$. [Fecha de publicación: 01/11/2005].

Rivera Álvarez, J. Ma: "La capacidad de obrar suficiente en el patrimonio protegido de las personas con discapacidad”, en RDP, enero-febrero 2006, págs. 83-102.

Rubio Torrano, E.: "Convención sobre los derechos de las personas con discapacidad", en Aranzadi Civil, 2008, núm. 14, págs. 11-13.

Salazar Murillo, J.: "Reconocimiento legal de la discapacidad", en Los derechos de las personas con discapacidad, Vol. I Aspectos jurídicos, Laorden, J. (dir.) y Terreros, J.L. (coord.), CGPJ, Madrid, 2007, págs. 735-777.

SÁnChez-Calero ArRibas, B.: "La administración y la supervisión del patrimonio protegido creado por la ley 41/2003, de 18 de noviembre, de protección patrimonial de las personas con discapacidad", en RCDI, No 695, 2006, págs. 1057-1100.

Villagrasa Alcaide, C.: El envejecimiento de la Población y la Protección Jurídica de las Personas Mayores, Barcelona 2002.

Vivas Tesón, I.: La protección económica de la discapacidad, Bosch, Barcelona, 2009. 